\title{
Obesity, Inflammation, Dectin-1 and Exercise Training
}

Ayoub Saeidi ${ }^{1}$, Anthony C Hackney ${ }^{2}$, Vahid Arab-yarmohammadi ${ }^{3}$, Lida Moradi ${ }^{4}$, Saman Pashaei ${ }^{5}$, Abderraouf Ben Abderrahmane ${ }^{6}$ and Hassane Zouhal ${ }^{\star}$

${ }^{1}$ Exercise Biochemistry Division, Faculty of Physical Education and Sport Sciences, University of Mazandaran, Babolsar, Iran

${ }^{2}$ Department of Exercise \& Sport Science, University of North Carolina, Chapel Hill, NC, United States

${ }^{3}$ Department of Molecular and Cell Biology, Faculty of Basic Sciences, University of Mazandaran, Iran

${ }^{4}$ Department of Physical Education and Sports Sciences, North Tehran Branch, Islamic Azad University, Iran

${ }^{5}$ Physical Education Department, Islamic Azad University, Saghez branch, Iran

${ }^{6}$ Laboratory of Biomonitoring of the Environment, Faculty of Science of Bizerte, University of Carthage, Tunisia

${ }^{7}$ Movement, Sport and Health Sciences (M2S), UFR-STAPS, University of Rennes 2, Rennes, France

"Corresponding author: Professor Hassane Zouhal, Movement, Sport and Health Sciences (M2S), UFR-STAPS, University of Rennes 2, Av. Charles Tillon, Campus la Harpe, 35044 Rennes, France, Tel: +33 29914 17 65; E-mail: hassane.zouhal@univ-rennes2.fr

Received date: February 19, 2018; Accepted date: March 12, 2018; Published date: March 16, 2018

Copyright: (C) 2018 Saeidi A, et al. This is an open-access article distributed under the terms of the Creative Commons Attribution License, which permits unrestricted use, distribution, and reproduction in any medium, provided the original author and source are credited.

\section{Letter to Editor}

Obesity is one of the most important risk factors in the development of the metabolic syndrome, type 2-diabetes and cardiovascular disease. In fact, new evidence suggests the linkage between obesity and diabetes is a cause and effect relationship [1]. The activation of inherent immune pathways in adipose tissue (AT) is associated with obesity and insulin resistance, and subsequent macrophage proliferation can lead to further inflammation of this tissue. Dectin-1 is a member of the Ctype lectin receptor (CLR) family and is one of the interacting and influencing factors expressed by macrophages and dendrite cells (DCs). Hence it potentially plays an important role in inflammation and insulin resistance development in humans [2].

Dectin-1 is a transmembrane signaling receptor that mediates various cellular functions, from fungal binding - uptake and killing, to inducing the production of select cytokines and chemokines. Dectin-1 requires interferon regulatory factor 5 (IRF5) for immune responsiveness [3], and IRF5 is necessary for differentiation of M1 AT macrophages, which play a major role in obesity-induced insulin resistance [4]. Dectin-1 therefore may be a key factor in the development of obesity-associated inflammation and insulin resistance. Since Dectin-1 is highly expressed in macrophages and DCs, we hypothesize that it modulates AT macrophage function and phenotype, contributing to the development of obesity and insulin resistance. To this end, Dectin-1 does affect macrophage polarization by activating IRF5 in the Dectin-Syk pathway [3]; and, the Dectin-1 adaptor molecules Spleen tyrosine kinase (Syk) and IRF5 are upregulated in the AT of obese mice. Collectively these findings support that Dectin-1 activation can contribute to the development of insulin resistance [2].

Interestingly, exercise training is well noted as one of the most effective behavioral factors in the prevention of obesity, diabetes and chronic inflammation [5,6]. Numerous studies have examined the effect of exercise training on diabetic and obese patients as well as cardiovascular patients, confirming that such training is able to reduce insulin resistance, obesity, inflammatory biomarkers and adipokines such as leptin, retinol binding protein [4], resistin (all associated with insulin resistance), while at the same time increasing adiponectin [7-9]. Research also supports exercise training to improve overall immune function by converting AT M1 macrophages to M2 forms and in turn mitigating obesity-induced inflammation [10]. To this point, Ruffino et al. demonstrated an increased M2 biomarker expression in human following participation in an 8-week walking intervention program [11]. This exercise effect on M2 expression occurred specifically within monocytes, and additionally IL-10, Dectin-1, and IL-1Ra, were all found to increase following the intervention [11]. Collectively, the aforementioned points highlight the positive effect of exercise training on obesity, diabetes and inflammation risk factors $[5,6,12]$; and, in turn suggest extensive research on the effect of exercise training on Dectin-1 is warranted - but, as of yet remains essentially unexamined. The study of Dectin-1 and exercise may provide new insight and important understanding about the connections between, and prevention of obesity, insulin resistance and related diseases. We encourage exercise immunology researchers to examine the theoretical constructs present here and test the hypothesis put forward.

\section{References}

1. Esser N, Legrand-Poels S, Piette J, Scheen AJ, Paquot N (2014) Inflammation as a link between obesity, metabolic syndrome and type 2 diabetes. Diabetes Res Clin Pract 105: 141-150.

2. Castoldi A, Andrade-Oliveira V, Aguiar CF, Amano MT, Lee J, et al. (2017) Dectin-1 Activation Exacerbates Obesity and Insulin Resistance in the Absence of MyD88. Cell Rep 19: 2272-2288.

3. Del Fresno C, Soulat D, Roth S, Blazek K, Udalova I, et al. (2013) Interferon- $\beta$ production via Dectin-1-Syk-IRF5 signaling in dendritic cells is crucial for immunity to C. albicans. Immunity 38: 1176-1186.

4. Krausgruber T, Blazek K, Smallie T, Alzabin S, Lockstone H, et al. (2011) IRF5 promotes inflammatory macrophage polarization and TH1-TH17 responses. Nat Immunol 12: 231-238.

5. Youssef H, Groussard C, Pincemail J, Moussa E, Jacob C, et al. (2009) Exercise-induced oxidative stress in overweight adolescent girls: roles of basal insulin resistance and inflammation and oxygen overconsumption. Int J Obes (Lond) 33: 447.

6. Zouhal H, Lemoine-Morel S, Mathieu ME, Casazza GA, Jabbour G (2013) Catecholamines and obesity: effects of exercise and training. Sports Med 43: 591-600.

7. Lakka TA, Laaksonen DE (2007) Physical activity in prevention and treatment of the metabolic syndrome. Appl Physiol Nutr Metab 32: 76-88.

8. Bassuk SS, Manson JE (2005) Epidemiological evidence for the role of physical activity in reducing risk of type 2 diabetes and cardiovascular disease. J Appl Physiol 99: 1193-1204.

9. Pedersen BK (2006) The anti-inflammatory effect of exercise: its role in diabetes and cardiovascular disease control. Essays Biochem 42: 105-117.

10. Gleeson M, Bishop N, Walsh N (2013) Exercise immunology. 
Citation: Saeidi A, Hackney AC, Arab-yarmohammadi V, Moradi L, Pashaei S, et al. (2018) Obesity, Inflammation, Dectin-1 and Exercise Training. J Diabetes Metab 9: 788. doi:10.4172/2155-6156.1000788

Page 2 of 2

11. Ruffino J, Davies N, Morris K, Ludgate M, Zhang L, et al. (2016) Moderate-intensity exercise alters markers of alternative activation in circulating monocytes in females: a putative role for PPAR $\gamma$. Eur J Appl Physiol 116: 1671-1682.
12. McMurray RG, Hackney AC (2005) Interactions of metabolic hormones, adipose tissue and exercise. Sports Med 35: 393-412. 